\title{
Oncologic and obstetric outcomes of fertility- sparing surgery for borderline ovarian tumors in women of reproductive age: a retrospective cohort study
}

\section{Rui Sun}

First Affiliated Hospital of Nanjing Medical University

Chengyan Luo

First Affiliated Hospital of Nanjing Medical University

\section{Yi Jiang}

First Affiliated Hospital of Nanjing Medical University

\section{Shulin Zhou}

First Affiliated Hospital of Nanjing Medical University

\section{Yicong Wan}

First Affiliated Hospital of Nanjing Medical University

\section{Wenjun Cheng ( $\square$ wenjunchengdoc@163.com )}

Jiangsu Province Hospital and Nanjing Medical University First Affiliated Hospital https://orcid.org/0000-0002-3872-4384

\section{Research}

Keywords: Borderline ovarian tumor, Fertility-sparing surgery, Staging surgery, Survival state, Live birth

Posted Date: July 2nd, 2020

DOI: https://doi.org/10.21203/rs.3.rs-38990/v1

License: (c) (i) This work is licensed under a Creative Commons Attribution 4.0 International License. Read Full License 


\section{Abstract \\ Objective}

To retrospectively evaluate the oncologic and obstetric outcomes of fertility-sparing surgery (FSS) for borderline ovarian tumors(BOT).

\section{Methods}

132 patients with borderline ovarian tumors were divided into the incompletely staging surgery (ISS) group and the completely staging surgery (CSS) group. The overall survival and disease-free survival curves were determined using the Kaplan-Meier method. The Cox proportional hazards method was used to assess the association between the variables and live birth and multivariate analysis to identify the independent associations.

\section{Results}

Chi-square and Kaplan-Meier analyses showed no significant differences in overall survival between the two groups ( $p=1.000$ and $p=0.716$, respectively). The CSS group had fewer relapses and longer diseasefree survival than ISS $(p=0.003)$. There was no statistical difference in live birth rate between two groups (crude odds ratio $=0.885,95 \% \mathrm{Cl} 0.411-1.903, p=0.755$; adjusted odds ratio $=0.848,95 \% \mathrm{Cl} 0.366-1.963$, $p=0.700$ ). Age was the only independent risk factor for live birth (adjusted odds ratio $=0.902,95 \% \mathrm{Cl}$ $0.823-0.988, p=0.027)$. Mean live birth intervals after FSS was $31.86 \pm 19.325$ months.

\section{Conclusions}

CSS significantly increased the disease-free survival time of BOT and reduced the relapse risk. However, CSS had a slightly negative and statistically insignificant association with live birth.

\section{Introduction}

Borderline ovarian tumours (BOTs) are characterised by complex papillary architecture, multilayered epithelium with tufting, mild nuclear atypia, and modestly increased mitotic activity. They do not exert destructive stromal invasion ${ }^{[1]}$ and account for approximately $10-15 \%$ of all ovarian epithelial tumors ${ }^{[2,}$ 3].

The incidence of BOTs has been rising over the past decades ${ }^{[4]}$. Epidemiologic data indicate that onethird of BOT patients are younger than 40 years ${ }^{[5,6]}$. Nearly $70 \%$ of the cases are generally diagnosed as International Federation of Gynecology and Obstetrics (IFGO) stage I with a 5-year survival rate of 95$97 \%{ }^{[7]}$.Given the young age and the good prognosis of BOTs, fertility-sparing surgery (FSS) is normally 
performed under fully informed consent for young women who desire fertility ${ }^{[8]}$ to preserve the uterus and at least one ovary with or without staging surgery. However, it remains unclear that the increased risk exposes patients with FSS, especially those who undergo ISS, to a potential effect on survival state and live birth.

The aim of this study was to evaluate the oncologic and obstetric outcomes in women of reproductive age who were treated for BOTs with staging fertility-sparing surgery and to assess the role of staging surgery in fertility-sparing surgery.

\section{Material And Methods}

The medical records of all consecutive patients treated with FSS for BOTs from January 2000 to August 2017 at the First Affiliated Hospital of Nanjing Medical University were retrospectively reviewed. Excluded were patients suffering from a primary malignant tumor in another part of the body or of other malignant ovarian cell types, older than 40 years or lost to follow-up within one month after the initial surgery.

FSS preserved the uterus and minimally one ovary, with or without staging surgery. For ovary preservation, the patient underwent one of the following surgical procedures: unilateral adnexectomy (UA), unilateral cystectomy (UC), unilateral adnexectomy with contralateral cystectomy (UA + CC), and bilateral cystectomy (BC). The procedure of CSS included careful inspection of the peritoneal surfaces, peritoneal washing, random or oriented multiple biopsies and infracolic omentectomy. Systematic appendectomy was also a criterion for complete staging of mucinous BOT.

The pathology images were reviewed by two independent pathologists. Staging of the disease was retrospectively performed according to IFGO staging system for ovarian carcinoma (2014). The stage of ISS was evaluated based on the patients' operative records and the available pathologic findings, with the unevaluated areas negative for metastatic lesions. Early disease was defined as IFGO stages IA-IB, and advanced disease as IFGO stages IC and above.

The decision of adjuvant chemotherapy was made based on the ovarian cyst rupture, positive pelvic washing data, lymph node metastasis status, invasive implants, and the extent of disease.

The time of overall survival was calculated from the date of the initial operation to the last follow-up or until death. The time of disease-free survival was calculated from the date of the initial operation to the date of recurrence.

After the initial treatment, patients were followed up once a month for the first six months, every three months for the next six months, every six months for the next two to five years, and every year thereafter. Recurrence was defined by clinical and/or imaging evidence and confirmed pathologically. Telephone interviews were also conducted to assess obstetric outcomes such as pregnancy attempts, delivery, and the use of assisted reproductive technology. 


\section{Statistical analysis}

The clinical features of the two groups, including age at diagnosis, histological type, micro interstitial infiltrates, IFGO stage, infertility, postoperative chemotherapy, surgery procedure, were compared and analyzed. Categorical variables were expressed as number (\%) and tested by Chi-square test or Fisher exact test. Continuous variables were presented as mean \pm standard deviation (SD) and tested by T-test, or Whitney U test (for variables with an abnormal distribution). The overall survival (OS) and disease-free survival (DFS) curves were determined using the Kaplan-Meier method and compared using the Log-rank test. The associations of the variables with live birth and intervals after the initial surgery were assessed using the Cox proportional hazards method; multivariate analysis was used to identify independent associations. A $p$-value of $\leq 0.05$ in a two-sided test was statistically significant. All statistical analyses were performed using IBM SPSS statistics 17.

\section{Results}

\section{Patient characteristics}

During the study period, 147 women with BOTs who received primary fertility-sparing surgical treatment were documented (Fig. 1). Excluded were the women whose surgery details were missing and those who were lost to follow-up within one month after the initial surgery. Finally, 132 women were included in the study (Table 1). Of the 132 patients, 54 undergone CSS and 78 undergone ISS. There were no significant differences in terms of age, histological type, peritoneal implantation, IFGO stage and postoperative chemotherapy between the two groups. There were significant differences in surgery procedure $(p<$ $0.001)$. 
Table 1

Baseline characteristics of patients

\begin{tabular}{|c|c|c|c|}
\hline & $\operatorname{css}(n=54)$ & ISS( $n=78)$ & $p$ value \\
\hline Age $($ mean $\pm S D)$ & $27.00 \pm 5.987$ & $27.95 \pm 5.422$ & 0.345 \\
\hline Histological type (\%) & & & 0.254 \\
\hline serous & $30(55.6 \%)$ & $51(65.4 \%)$ & \\
\hline mucinous & $24(44.4 \%)$ & $27(34.6 \%)$ & \\
\hline Peritoneal implantation (\%) & & & 0.635 \\
\hline yes & $10(18.5 \%)$ & $12(15.4 \%)$ & \\
\hline no & $44(81.5 \%)$ & $66(84.6 \%)$ & \\
\hline FIGO stage (\%) & & & 0.098 \\
\hline$I A+I B$ & $36(66.7 \%)$ & $62(79.5 \%)$ & \\
\hline$\geq I C$ & 18(33.3\%) & $16(20.5 \%)$ & \\
\hline Infertility (\%) & & & 0.635 \\
\hline yes & $8(14.8 \%)$ & $14(17.9 \%)$ & \\
\hline no & $46(85.2 \%)$ & $64(82.1 \%)$ & \\
\hline Postoperative chemotherapy (\%) & & & 0.458 \\
\hline yes & $11(20.4 \%)$ & $12(15.4 \%)$ & \\
\hline no & $43(79.6 \%)$ & $66(84.6 \%)$ & \\
\hline Surgery procedure (\%) & & & $<0.001$ \\
\hline UA & $41(75.9 \%)$ & $32(41.0 \%)$ & \\
\hline UC & $3(5.6 \%)$ & $31(39.7 \%)$ & \\
\hline $\mathrm{UA}+\mathrm{CC}$ & $10(18.5 \%)$ & $7(9.0 \%)$ & \\
\hline $\mathrm{BC}$ & $0(0.0 \%)$ & $8(10.3 \%)$ & \\
\hline Survival state & & & 1.000 \\
\hline dead & $1(1.9 \%)$ & $1(1.3 \%)$ & \\
\hline alive & $53(98.1 \%)$ & 77(98.7\%) & \\
\hline OS(months) & $65.049 \pm 26.077$ & $75.856 \pm 43.269$ & 0.076 \\
\hline Recurrence & & & $<0.001$ \\
\hline
\end{tabular}




\begin{tabular}{|llll|}
\hline & CSS( $\mathbf{n}=\mathbf{5 4 )}$ & ISS( $\mathbf{n}=\mathbf{7 8})$ & p value \\
\hline yes & $7(13.0 \%)$ & $40(51.3 \%)$ & \\
\hline no & $47(87.0 \%)$ & $38(48.7 \%)$ & \\
\hline DFS(months) & $61.113 \pm 26.023$ & $49.431 \pm 36.261$ & 0.033 \\
\hline CSS: completely staging surgery & & \\
\hline ISS: incompletely staging surgery & & \\
\hline SD: standard deviation & & \\
\hline FIGO: International Federation of Gynecology and Obstetrics \\
\hline UA: unilateral adnexectomy & \\
\hline UC: unilateral cystectomy & \\
\hline UA + UC: unilateral adnexectomy with contralateral cystectomy \\
\hline BC: bilateral cystectomy \\
\hline OS: overall survival \\
\hline DFS: disease-free survival
\end{tabular}

\section{Oncologic outcomes}

The median follow-up was 67.233 (range: 8.60-223.40) months. For the entire series, 47 patients $(47 / 13235.6 \%)$ had recurrence at 3.77 to 145.60 months after the initial surgery. The median interval of disease-free survival was 50.583 months. There were two disease-related deaths, and other patients were alive until the end of the follow-up. The total 5-year disease-free survival and overall survival rates were $69.6 \%$ and $99.2 \%$, respectively. Chi-square analysis and Kaplan-Meier analysis showed no significant differences in overall survival between the CSS and ISS groups ( $p=1.000$ and 0.716 , respectively) (Table 1 and Fig. 2a). The recurrence rate was significantly higher in the ISS group than the CSS group $(51.3 \% \%$ vs. $13.0 \%, p<0.001)$. The Kaplan-Meier analysis revealed that the CSS group suffered fewer relapses and longer disease-free survival time than the ISS group $(p=0.003)$ (Fig. 2b).

\section{Obstetric outcomes}

Telephone interviews were conducted with all 132 patients (including the family members of the two dead patients) after FSS. Among them, 70 attempted to conceive were included in this part of the study (Table 2) and 62 women who did not try to conceive were removed. There were no significant differences in terms of staging surgery, IFGO stage, histological type, peritoneal implantation, postoperative menstruation, chemotherapy and infertility between the live birth group and the non-live-birth group. The two groups had significant differences in age and surgery procedure ( $p=0.047$ and 0.032 , respectively). 
Table 2

Characteristics of patients who attempted to conceive after the FSS

\begin{tabular}{|c|c|c|c|}
\hline & $\begin{array}{l}\text { Women with live births }(n= \\
\text { 34) }\end{array}$ & $\begin{array}{l}\text { Women without live births ( } \mathrm{n}= \\
\text { 36) }\end{array}$ & $\underset{\text { value }}{p}$ \\
\hline Age $($ mean $\pm S D)$ & $26.62 \pm 3.908$ & $28.64 \pm 4.402$ & 0.047 \\
\hline Staging surgery & & & 0.385 \\
\hline CSS & $9(26.5 \%)$ & $13(36.1 \%)$ & \\
\hline ISS & $25(73.5 \%)$ & $23(63.9 \%)$ & \\
\hline Surgery procedure (\%) & & & 0.032 \\
\hline UA & $19(55.9 \%)$ & $14(38.9 \%)$ & \\
\hline UC & $13(38.2 \%)$ & $10(27.8 \%)$ & \\
\hline $\mathrm{UA}+\mathrm{CC}$ & $2(5.9 \%)$ & $8(22.2 \%)$ & \\
\hline $\mathrm{BC}$ & $0(0.0 \%)$ & $4(11.1 \%)$ & \\
\hline IFGO stage (\%) & & & 0.705 \\
\hline$I A+I B$ & $25(73.5 \%)$ & $25(69.4 \%)$ & \\
\hline$\geq I C$ & $9(26.5 \%)$ & $11(30.6 \%)$ & \\
\hline Histological type (\%) & & & 0.246 \\
\hline serous & $25(73.5 \%)$ & $28(77.8 \%)$ & \\
\hline mucinous & $9(26.5 \%)$ & $8(22.2 \%)$ & \\
\hline Peritoneal implantation & & & 0.231 \\
\hline yes & $7(20.6 \%)$ & $12(33.3 \%)$ & \\
\hline no & $27(79.4 \%)$ & $24(66.7 \%)$ & \\
\hline $\begin{array}{l}\text { Postoperative } \\
\text { menstruation }\end{array}$ & & & 0.845 \\
\hline regular & $20(58.8 \%)$ & $22(61.1 \%)$ & \\
\hline irregular & $14(41.2 \%)$ & $14(38.9 \%)$ & \\
\hline Chemotherapy & & & 0.208 \\
\hline yes & $6(17.6 \%)$ & $11(30.6 \%)$ & \\
\hline no & $28(82.4 \%)$ & $25(69.4 \%)$ & \\
\hline Infertility (\%) & & & 0.231 \\
\hline no & $27(79.4 \%)$ & $24(66.7 \%)$ & \\
\hline
\end{tabular}




\begin{tabular}{|c|c|c|c|}
\hline & $\begin{array}{l}\text { Women with live births }(n= \\
\text { 34) }\end{array}$ & $\begin{array}{l}\text { Women without live births }(n= \\
\text { 36) }\end{array}$ & $\begin{array}{l}p \\
\text { value }\end{array}$ \\
\hline yes & $7(20.6 \%)$ & $12(33.3 \%)$ & \\
\hline \multicolumn{4}{|c|}{ FSS: fertility-sparing surgery } \\
\hline \multicolumn{4}{|c|}{ CSS: completely staging surgery } \\
\hline \multicolumn{4}{|c|}{ ISS: incompletely staging surgery } \\
\hline \multicolumn{4}{|l|}{ SD: standard deviation } \\
\hline \multicolumn{4}{|c|}{ FIGO: International Federation of Gynecology and Obstetrics } \\
\hline \multicolumn{4}{|c|}{ UA: unilateral adnexectomy } \\
\hline \multicolumn{4}{|l|}{ UC: unilateral cystectomy } \\
\hline \multicolumn{4}{|c|}{ UA + UC: unilateral adnexectomy with contralateral cystectomy } \\
\hline BC: bilateral cystectomy & & & \\
\hline
\end{tabular}

To find out the factors affecting the live birth intervals after FSS, all the listed covariates in Table 3 were entered into the initial Cox proportional hazard model with backward logistic stepwise regression method. The final hazard regression model (Table 3 ) showed that age, surgery procedure and chemotherapy was statistically related to live birth intervals after FSS. Yet only age was identified as the independent risk factor for patients' live births in the multivariate analysis (adjusted odds ratio $=0.902,95 \% \mathrm{Cl} 0.823-$ $0.988, p=0.027$ ). Adjusted analysis was not possible for $\mathrm{BC}$ because no cases were observed in the $\mathrm{BC}$ group. 
Table 3

Cox proportional hazard regression models for live birth intervals.

\begin{tabular}{|lll|}
\hline & $p$ value & $95 \% \mathrm{Cl}$ \\
\hline Age & 0.027 & $0.823-0.988$ \\
\hline Surgery procedure & 0.479 & \\
\hline UC & 0.626 & $0.408-1.715$ \\
\hline UA + CC & 0.117 & $0.070-1.345$ \\
\hline BC & 0.979 & \\
\hline Chemotherapy & 0.111 & $0.191-1.185$ \\
\hline UC: unilateral cystectomy & & \\
\hline UA + UC: unilateral adnexectomy with contralateral cystectomy \\
\hline BC: bilateral cystectomy & \\
\hline
\end{tabular}

Univariate and multivariate analysis showed no statistical differences in live births between CSS and ISS. The live birth rate was $40.9 \%$ (9/22) in CSS, compared with $52.1 \%$ (25/48) in ISS group, indicating no statistical significance $(p=0.385)$ between the two groups. The crude odds ratio for CSS was 0.885 ( $p=$ $0.755,95 \% \mathrm{Cl}: 0.411-1.903)$; the adjusted odds ratio decreased to $0.848(p=0.700,95 \% \mathrm{Cl}=0.366-$ 1.963) after the adjustment for age, chemotherapy and surgery procedure.

Of the 70 patients who attempted to conceive after FSS, 34 patients (48.5\%) gave birth successfully. Live birth intervals after FSS was $31.86 \pm 19.325$ (range: $4.93-82.17$ ) months. Two patients had UA during pregnancy and gave birth successfully. Among the 34 patients who gave birth, 27 (27/34, 79.4\%) were conceived naturally, while seven $(7 / 34,20.6 \%)$ underwent ovulation induction and in vitro fertilization (IVF) treatment. These pregnancies resulted in 31 full-term deliveries and three premature deliveries. Nineteen patients had cesarean section and 15 had spontaneous delivery. The hydatid mole was seen in one case, and ongoing pregnancy in one at the time of analysis.

\section{Discussion}

Surgical staging of BOTs is controversial. Some people suggest that re-staging surgery and full staging surgery is not necessary for all BOTs. Kimio ${ }^{[9]}$ believed that there was no significant difference in patients' survival between those who underwent re-staging surgery and those who did not. A French multi-centered study ${ }^{[10]}$ found no difference in recurrence rates between patients who received restaging operations and those who did not. For patients who underwent restaging, the mean recurrence time was $40 \pm 19.9$ months after surgery, compared with $30.9 \pm 36.3$ months for those who did not undergo restaging (no significant difference). Similarly, in a series of 233 BOT patients without re-staging procedures, the patients who had undergone complete staging suffered fewer relapses than those with incomplete 
staging ( $5.1 \%$ vs $12.3 \%)$, but this difference was not statistically significant according to the multivariate analysis ${ }^{[11]}$. Margarita suggested that the benefits of complete staging in BOT patients could be limited because: a) it might not affect the decision of adjuvant treatment as this was not a standard care; and $b$ ) most recurrences could be salvaged ${ }^{[12,13]}$. However, other people hold a different point of view. A metaanalysis of 2770 BOT cases from 18 observational studies showed that CSS significantly reduced recurrence (the pooled odds ratio for CSS and recurrence: $0.64,95 \%$ confidence interval: $0.47-0.87, p<$ $0.05)^{[14]}$. A large cohort study on BOT of the Arbeitsgemeinschaft Gynaekologische Onkologie (AGO ROBOT study) confirmed ISS as an independent negative prognostic factor for disease recurrence, apart from other factors such as higher IFGO stage, residual tumour, and fertility preservation ${ }^{[15]}$. Generally, fertility preservation for BOT patients carries a good prognosis ${ }^{[16-19]}$. But few studies have discussed the safety and necessity of CSS for BOTs in FSS. As for ISS, we found that despite the high recurrence rate, the overall survival and prognosis were not affected. Chi-square analysis and Kaplan-Meier analysis showed no significant differences in survival between CSS and ISS ( $p=1.000$ and 0.716 , respectively), and CSS significantly increased the disease-free survival time of BOT $(p=0.000)$ and reduced the risk of relapse $(51.3 \%$ vs. $13.0 \%, p=0.000)$.

Many studies were conducted regarding the pregnancy rates of BOT patients after FSS, but few addressed live birth rates. $\mathrm{Zhao}^{[20]}$ reported a total pregnant rate of $33.8 \%$. Lee also reported that 26 of the 32 patients (81.3\%) had successful pregnancies[16]. A systematic review of 230 articles on conservative management of BOTs reported the pregnancy rates ranged from $32-88 \%$, and the pooled estimate for spontaneous pregnancies was $54 \%\left(95 \% \mathrm{Cl}: 38-70 \%, \mathrm{I}^{2}=91 \%\right)^{[21]}$. Higher pregnancy rates were reported in Asian series where the proportion of conservatively treated mucinous tumor was higher: pregnancy rates were $88 \%$ according to Song et al ${ }^{[22]}$, and $73 \%$ according to Park et al ${ }^{[23]}$. In our series, $48.5 \%(34 / 70)$ of the cases had live births after FSS. The birth intervals after FSS was $31.86 \pm 19.325$ (range: $4.93-82.17$ ) months. Fauvet ${ }^{[24]}$ reported that the median interval from surgery to pregnancy was $28.6 \pm 24.6$ (range: $4-89$ ) months. The results in our study corresponded with the literatures. In general, positive reproductive treatment is needed for fertility-sparing patients of older age to help them conceive as early as possible. For those who want to conceive naturally, fertility guidelines can be introduced at $31.86 \pm 19.325$ months after surgery.

A nomogram developed to predict live birth for BOT women after FSS found factors such as FIGO stage, age at diagnosis, histological subtype and surgery type could impact live birth and fertility ${ }^{[25]}$. The influence of age on live birth cannot be ignored. Fauvet ${ }^{[26]}$ reported that on average, the women who conceived were younger than those who did not conceive $(26.7 \pm 5.6$ years vs. $32.3 \pm 6.5$ years; $p=0.001)$, yet the two subgroups did not differ significantly in terms of nulliparity proportion, the history of infertility or ovarian surgery, preoperative tumor marker levels, tumor size, or the type of conservative treatment. Previous studies ${ }^{[26]}$ showed that age at initial treatment was the only determinant of fertility. In patients aged 35 years, the pregnancy rate was $42 \%$, which was significantly higher (by $20 \%$ ) than that of patients aged 35 to 40 years. In our study, the final COX model showed that age, surgery procedure and chemotherapy was statistically related to live birth and intervals after FSS during follow-up. But only age 
was identified as an independent risk factor for live birth, which was similar to previous studies.

Furthermore, we find that the live birth rate of women with ISS was higher than that of women with CSS, but the difference was not statistically significant.

\section{Strengths And Limitations}

Our study is limited by the inherent flaws of a retrospective design, as well as a referral bias of patients who received treatment and follow-up at a single tertiary cancer center. Another limitation dictated by the rarity of these tumors is an extended study period, which exposes the study cohort to shifts in classification and management. One should consider these limitations in assessing our findings.

\section{Conclusion}

FSS with CSS or ISS both seemed safe and feasible for young women who desire fertility preservation. CSS could significantly increase the disease-free survival time of BOT and reduce the risk of relapse, while there was no significant difference in overall survival between CSS and ISS. Besides, CSS had slightly negative and statistically insignificant association with live birth. For young patients who required to conceive naturally, assisted reproductive technology could be introduced until $31.86 \pm 19.325$ months after surgery. However, positive reproductive treatment should be used for fertility-sparing patients of older age to help them conceive as early as possible.

\section{Abbreviations}

incompletely staging surgery (ISS)

completely staging surgery (CSS)

fertility-sparing surgery (FSS)

borderline ovarian tumors (BOT).

International Federation of Gynecology and Obstetrics (IFGO)

standard deviation (SD)

overall survival (OS)

disease-free survival (DFS)

unilateral adnexectomy (UA)

unilateral cystectomy (UC)

unilateral adnexectomy with contralateral cystectomy $(\mathrm{UA}+\mathrm{CC})$ 
bilateral cystectomy $(\mathrm{BC})$

\section{Declarations}

\section{Availability of data and materials}

The datasets analysed during the current study are not publicly available due to further study but are available from the corresponding author on reasonable request.

\section{Ethics approval and consent to participate}

The study was approved by the ethics committee of the First Affiliated Hospital, Nanjing Medical University, Jiangsu Province Hospital. Approval number No. 2018-SRFA-052. All participants provided an informed written consent after explaining the aim of the study, the procedure \& the potential hazards.

\section{Consent for publication}

Not applicable

\section{Competing interests}

The authors declare that they have no competing interests.

\section{Funding}

This work is supported by the National Natural Science Foundation of China (8187101839), and the Jiangsu Province Medical Innovation Team (CXTDA2017008).

\section{Author contributions}

Rui Sun: project development, data collection, data analysis, manuscript writing. Luocheng Yan: project development, data collection, data analysis. Yi Jiang: data collection, manuscript editing. Yicong Wan: manuscript writing. Shulin Zhou: data collection. Wenjun Cheng: project development, manuscript writing. All authors read and approved the final manuscript.

\section{Acknowledgements}

None

\section{References}


1. Bocker W. [WHO classification of breast tumors and tumors of the female genital organs: pathology and genetics][J]. Verh Dtsch Ges Pathol. 2002;86:116-9.

2. Harris R, Whittemore AS, Itnyre J. Characteristics relating to ovarian cancer risk: collaborative analysis of 12 US case-control studies. III. Epithelial tumors of low malignant potential in white women. Collaborative Ovarian Cancer Group[J] Am J Epidemiol. 1992;136(10):1204-11.

3. Morice P, Uzan C, Fauvet R, et al. Borderline ovarian tumour: pathological diagnostic dilemma and risk factors for invasive or lethal recurrence[J]. Lancet Oncol. 2012;13(3):e103-15. DOI:10.1016/S1470-2045(11)70288-1.

4. Skirnisdottir I, Garmo H, Wilander E, et al. Borderline ovarian tumors in Sweden 1960-2005: trends in incidence and age at diagnosis compared to ovarian cancer[J]. Int J Cancer. 2008;123(8):1897-901. DOI:10.1002/ijc.23724.

5. Sherman ME, Berman J, Birrer MJ, et al. Current challenges and opportunities for research on borderline ovarian tumors[J]. Hum Pathol. 2004;35(8):961-70.

6. Sherman ME, Mink PJ, Curtis R, et al. Survival among women with borderline ovarian tumors and ovarian carcinoma: a population-based analysis[J]. Cancer. 2004;100(5):1045-52. DOI:10.1002/cncr.20080.

7. Tinelli R, Tinelli A, Tinelli FG, et al. Conservative surgery for borderline ovarian tumors: a review[J]. Gynecol Oncol. 2006;100(1):185-91. DOl:10.1016/j.ygyno.2005.09.021.

8. du Bois A, Trillsch F, Mahner S, et al. Management of borderline ovarian tumors[J]. Ann Oncol. 2016;27(Suppl 1):i20-2. DOI:10.1093/annonc/mdw090.

9. Ushijima K, Kawano K, Tsuda N, et al. Epithelial borderline ovarian tumor: Diagnosis and treatment strategy[J]. Obstet Gynecol Sci. 2015;58(3):183-7. DOI:10.5468/ogs.2015.58.3.183.

10. Fauvet R, Boccara J, Dufournet $C$, et al. Restaging surgery for women with borderline ovarian tumors: results of a French multicenter study[J]. Cancer. 2004;100(6):1145-51. DOI:10.1002/cncr.20098.

11. Wu TI, Lee CL, Wu MY, et al. Prognostic factors predicting recurrence in borderline ovarian tumors[J]. Gynecol Oncol. 2009;114(2):237-41. DOl:10.1016/j.ygyno.2009.05.018.

12. Romeo $M$, Pons $F$, Barretina $P$, et al. Erratum to: Incomplete staging surgery as a major predictor of relapse of borderline ovarian tumor[J]. World J Surg Oncol. 2016;14(1):226. DOI:10.1186/s12957016-0976-4.

13. Romeo $M$, Pons F, Barretina $P$, et al. Incomplete staging surgery as a major predictor of relapse of borderline ovarian tumor[J]. World J Surg Oncol. 2013;11:13. DOI:10.1186/1477-7819-11-13.

14. Shim SH, Kim SN, Jung PS, et al. Impact of surgical staging on prognosis in patients with borderline ovarian tumours: A meta-analysis[J]. Eur J Cancer. 2016;54:84-95.DOI:10.1016/j.ejca.2015.11.005.

15. du Bois A, Ewald-Riegler N, de Gregorio N, et al. Borderline tumours of the ovary: A cohort study of the Arbeitsgmeinschaft Gynakologische Onkologie (AGO) Study Group[J]. Eur J Cancer. 2013;49(8):1905-14. DOI:10.1016/j.ejca.2013.01.035. 
16. Lee SY, Choi MC, Kwon BR, et al. Oncologic and obstetric outcomes of conservative surgery for borderline ovarian tumors in women of reproductive age[J]. Obstet Gynecol Sci. 2017;60(3):289-95. DOI:10.5468/ogs.2017.60.3.289.

17. Lou T, Yuan F, Feng Y, et al. The safety of fertility and ipsilateral ovary procedures for borderline ovarian tumors[J]. Oncotarget. 2017;8(70):115718-29. DOI:10.18632/oncotarget.23021.

18. Helpman L, Yaniv A, Beiner ME, et al. Fertility preservation in women with borderline ovarian tumors how does it impact disease outcome? A cohort study[J]. Acta Obstet Gynecol Scand. 2017;96(11):1300-6. DOI:10.1111/aogs.13203.

19. Lee SY, Choi MC, Kwon BR, et al. Oncologic and obstetric outcomes of conservative surgery for borderline ovarian tumors in women of reproductive age[J]. Obstet Gynecol Sci. 2017;60(3):289-95. DOI:10.5468/ogs.2017.60.3.289.

20. Zhao J, Liu C, Liu J, et al. Short-term Outcomes and Pregnancy Rate After Laparoscopic FertilitySparing Surgery for Borderline Ovarian Tumors: A Single-Institute Experience[J]. Int J Gynecol Cancer. 2018;28(2):274-8. DOI:10.1097/IGC.0000000000001170.

21. Darai E, Fauvet R, Uzan C, et al. Fertility and borderline ovarian tumor: a systematic review of conservative management, risk of recurrence and alternative options[J]. Hum Reprod Update. 2013;19(2):151-66. DOI:10.1093/humupd/dms047.

22. Song T, Hun CC, Lee YY, et al. Oncologic and reproductive outcomes of cystectomy compared with oophorectomy as a treatment for borderline ovarian tumours[J]. Hum Reprod. 2011;26(8):2008-14. DOI:10.1093/humrep/der119.

23. Park JY, Kim DY, Kim JH, et al. Surgical management of borderline ovarian tumors: The role of fertility-sparing surgery[J]. Gynecol Oncol. 2009;113(1):75-82. DOI:10.1016/j.ygyno.2008.12.034.

24. Fauvet R, Poncelet $C$, Boccara J, et al. Fertility after conservative treatment for borderline ovarian tumors: a French multicenter study[J]. Fertil Steril. 2005;83(2):284-90.

DOI:10.1016/j.fertnstert.2004.10.009. 525-526.

25. Ouldamer L, Bendifallah S, Naoura I, et al. Nomogram to predict live birth rate after fertility-sparing surgery for borderline ovarian tumours[J]. Hum Reprod. 2016;31(8):1732-7.

DOI:10.1093/humrep/dew137.

26. Fauvet $\mathrm{R}$, Poncelet $\mathrm{C}$, Boccara J, et al. Fertility after conservative treatment for borderline ovarian tumors: a French multicenter study[J]. Fertil Steril. 2005;83(2):284-90.

DOI:10.1016/j.fertnstert.2004.10.009. 525-526.

\section{Figures}




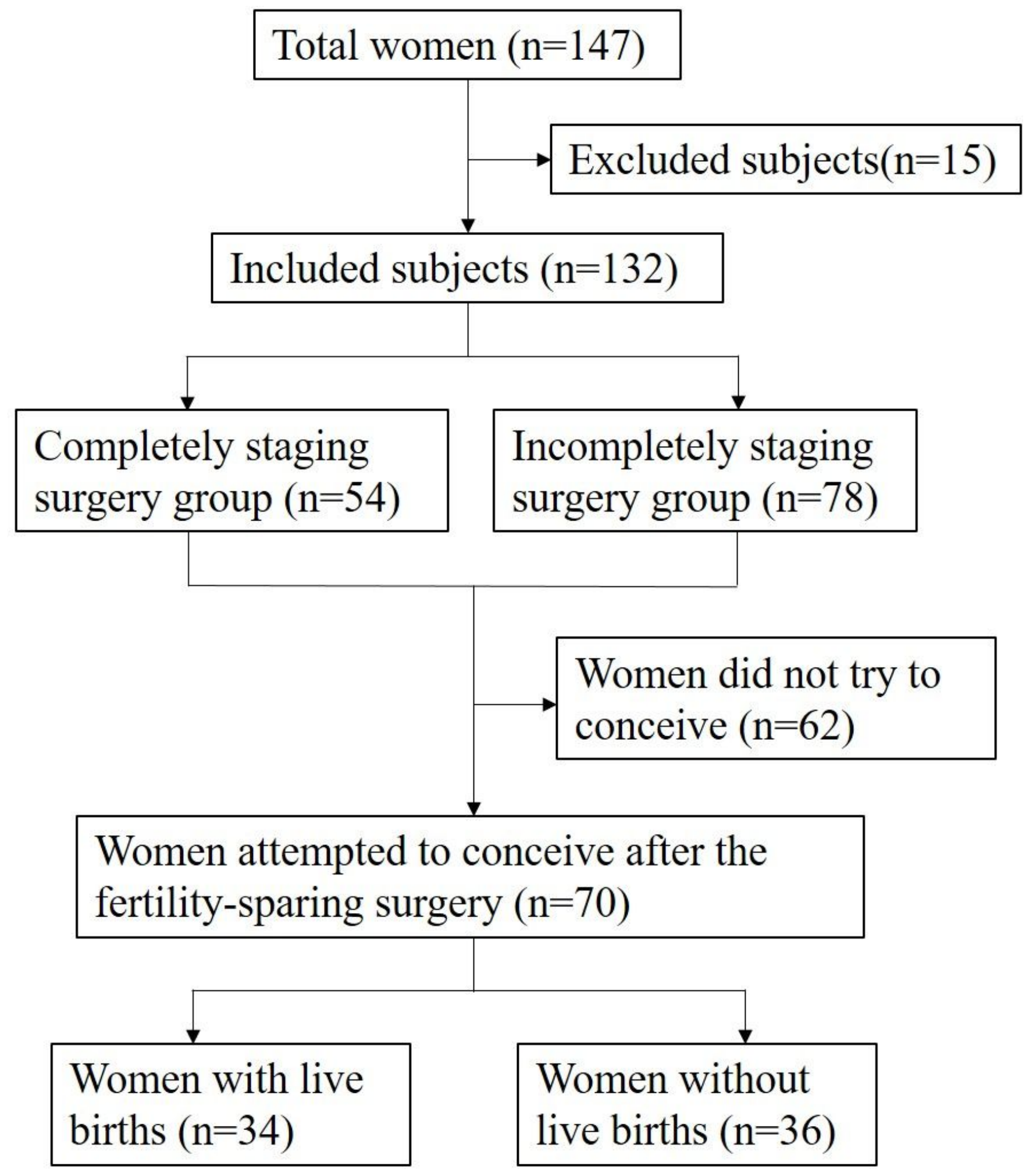

Figure 1

Study flow diagram of the paper 
a

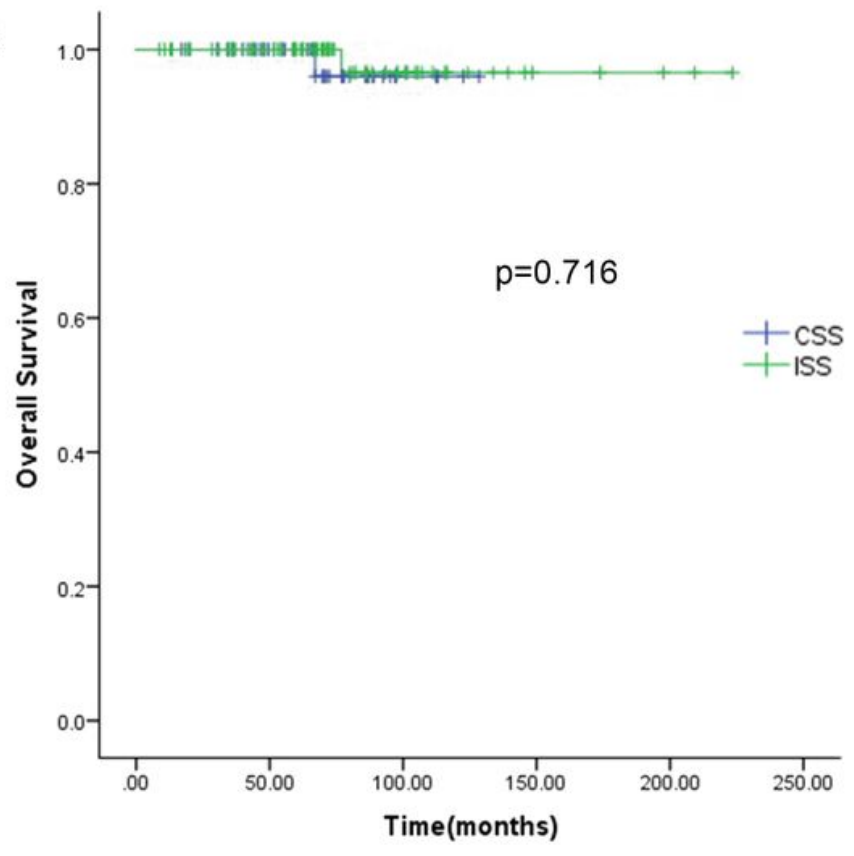

b

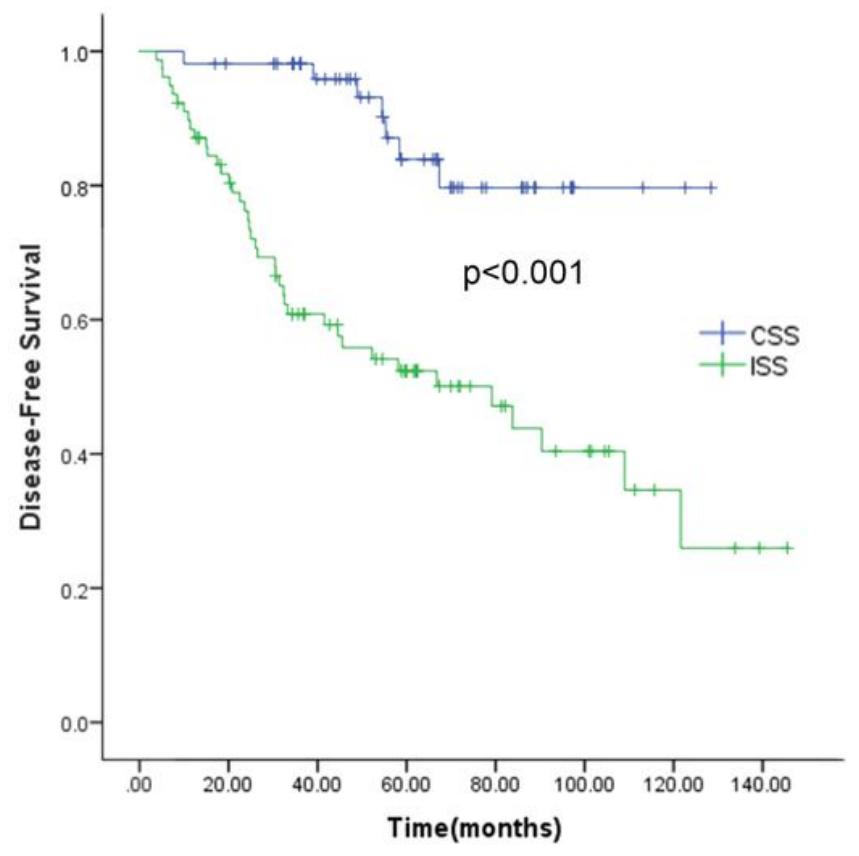

Figure 2

Survival curves in women with borderline ovarian tumors. (a)Overall survival comparing the incompletely staging surgery (ISS) group and the completely staging surgery (CSS) group. (b)Disease-free survival comparing the incompletely staging surgery (ISS) group and the completely staging surgery (CSS) group.

\section{Supplementary Files}

This is a list of supplementary files associated with this preprint. Click to download.

- coverletter.docx 